\title{
Analysis of the Climate inside Multi-span Plastic Greenhouses under Different Shade Strategies and Wind Regimes
}

\author{
Keshi He ${ }^{1}$, Dayue Chen ${ }^{1}$, Lijuan Sun ${ }^{2}$, Zhenyu Huang ${ }^{1 *}$, and Zhenglu Liu ${ }^{3}$ \\ ${ }^{1}$ Laboratory of Complex Dynamics Simulation, Department of Instrument Science and Engineering, School of Electronic, Information and Electrical \\ Engineering, Shanghai Jiao Tong University, Shanghai, 200240, China \\ ${ }^{2}$ Institute of Crop Science, Chinese Academy of Agricultural Sciences, Beijing, 100081, China \\ ${ }^{3}$ Shanghai Key Laboratory of Protected Horticultural Technology, Sunqiao Modern Agriculture Development Zone, Shanghai, 201210, China
}

\begin{abstract}
In this work, the effects of shade combination, shade height and wind regime on greenhouse climate were quantified. A two-dimensional (2-D) computational fluid dynamics (CFD) model was developed based on an 11-span plastic greenhouse in eastern China for wind almost normal to the greenhouse orientation. The model was first validated with air temperature profiles measured in a compartmentalized greenhouse cultivated with mature lettuce (Lactuca sativa L., 'Yang Shan'). Next, the model was employed to investigate the effect of shade combinations on greenhouse microclimate patterns. Simulations showed similar airflow patterns in the greenhouse under different shade combinations. The temperature pattern was a consequence of convection and radiation transfer and was not significantly influenced by shade combination. The use of shade screens reduced air velocity by $0.02-0.20 \mathrm{~m} \cdot \mathrm{s}^{-1}$, lowered air temperature by $0.2-0.8^{\circ} \mathrm{C}$ and raised the humidity level by $0.9-2.0 \%$ in the greenhouse. Moreover, it improved the interior climate homogeneity. The assessment of shade performance revealed that the external shade had good cooling and homogeneity performance and thus can be recommended. Furthermore, the effects of external shade height and wind regime on greenhouse climate parameters showed that external shade screens are suitable for installation within $1 \mathrm{~m}$ above roof level. They also demonstrated that, under external shade conditions, greenhouse temperature was reduced relative to unshaded conditions by $1.3^{\circ} \mathrm{C}$ under a wind speed of $0.5 \mathrm{~m} \cdot \mathrm{s}^{-1}$, whereas it was reduced by merely $0.5^{\circ} \mathrm{C}$ under a wind speed of $2.0 \mathrm{~m} \cdot \mathrm{s}^{-1}$. Therefore, external shading is more useful during periods of low wind speed.
\end{abstract}

Additional key words: natural ventilation, numerical simulation, shade combination, shade height, shade screen, solar radiation

\section{Introduction}

In eastern China, multi-span plastic greenhouses have been rapidly expanded for the horticultural production. These greenhouses, being traditional, low cost and simple structured, only rely on the natural ventilation system to manage inside climate. Under the local subtropical climate, greenhouse crop suffers from hot and sunny days with high-intensity solar radiation, high temperature and low wind speed during the growth cycle. During the period, natural ventilation is generally not sufficient for releasing the excess energy (Katsoulas et al., 2001). Hence, it is impossible to execute greenhouse crop production.

Considering the limited cooling performance of natural ventilation, other cooling methods have to be used in combination with natural ventilation (Katsoulas et al., 2001). In order to expand the production day, there is a growing trend to equip greenhouses with shade screens. These screens, which may be mounted internally or externally, attenuate the incoming solar radiation and avoid the direct damage of the intense sunshine to the crop's growth during hot days of summer periods. Meanwhile, they reduce the indoor heat losses and preserve the inner thermal insulation during cold days of winter periods.

\footnotetext{
*Comesponding author: bighuang@sjtu.edu.cn

※ Received 8 October 2013; Revised 12 March 2014; Accepted 2 April 2014. The authors wish to thank Shanghai Municipal Agriculture Commission for the financial support of the present work.

(C) 2014 Korean Society for Horticultural Science
} 
In the literature, many researchers investigated the shade system and its impact on greenhouse climate. In these researches, there are two aspects focused. The first is the analysis of the effect of shade parameter modification (e.g., shade combination, rate and level) on the air temperature, climate heterogeneity, spectral distribution and crop inside the greenhouse (Al-Arifi, 1999; Al-helal, 1998; Kitta et al., 2012; Kittas et al., 2003; Lee and Short, 1998; Montero et al., 2013; Piscia et al., 2012b; Sapounas et al., 2010; Vlamdimirova et al., 1996). The second is the investigations of the physical properties of shade materials (Cohen and Fuchs, 1999; Kittas and Baille, 1998; Miguel et al., 1997) and their impacts on greenhouse climate (Baxevanou et al., 2010; Kittas et al., 1999; Willits, 2000, 2001, 2003).

In the past decade, the CFD simulation has been developed into a powerful tool for studying greenhouse climate. Various physical mechanisms are incorporated into the CFD model one after another, which enhances the realism of the simulation. In recent CFD studies, many researchers started to incorporate the radiation model into the numerical simulation to map the complex inside climate induced by the radiative transfer. Therefore, many interesting phenomena such as night-time thermal behaviors (Montero et al., 2013; Muñoz et al., 2004; Piscia et al., 2012a) and day-time climate transient processes (Fidaros et al., 2010; Nebbali et al., 2012; Tong et al., 2009) occurred inside the greenhouse is revealed.

So far, most studies related to the effect of shade screens on greenhouse climate focused on the experimental investigation based on an analytical model. Few researchers employed the CFD simulation to explore the response of greenhouse climate factors to shade parameter (Al-Arifi, 1999; Al-helal, 1998; Lee and Short, 1998; Montero et al., 2013; Muñoz et al., 2004; Piscia et al., 2012a; Sapounas et al., 2010). However, these explorations provide limited guidance for these multi-span greenhouses in eastern China, owe to the differences of greenhouse design and outside climate condition. Therefore, it is still necessary to design the CFD model to investigate the greenhouse microclimate pattern and the shading performance with various scenarios under the local climate condition.

The aim of this study was to employ the CFD simulation to investigate the effects of shade combination, external shade height and wind regime on the climate in the natural ventilated greenhouse.

\section{Materials and Methods}

\section{Greenhouse Facilities and Experimental Designs}

The studied greenhouse is an 11-span plastic greenhouse covered with the low density polyethylene (LDPE) film (0.12 mm thickness). It is North-South (N-S) oriented and located in the Sunqiao Modern Agriculture Development Zone, Shanghai $\left(31^{\circ} 18^{\prime} \mathrm{N}, 121^{\circ} 63^{\prime} \mathrm{E}\right)$. Greenhouse geometrical characteristic is shown in Fig. 1A. Natural ventilation can be performed with 20 roof and 8 side openings. The greenhouse is divided into two independent compartments by a central plastic partition. The left one is the compartment I, whereas the right one is the compartment II that is equipped with the fan and pad system, the movable external and internal shade system, the movable internal curtain system, and the circulation fan system, as shown in Figs. $1 \mathrm{~B}$ and $1 \mathrm{C}$.

Two measurements were conducted in the rebuilding compartment (compartment II) to determine the indoor and outdoor climate parameters. One measurement (Exp 1) was carried out on 15:11-16:30, 6 Aug 2011, when the external shade system was fully closed. The other measurement (Exp 2) was executed on 12:50-14:00, 15 Aug 2011, when the external shade system was fully opened. During these experiments, greenhouse roof ventilation was performed, when the outside wind is almost normal to the greenhouse orientation.

\section{Plant Materials}

A total of 22 rows lettuces (Lactuca sativa L, 'Yang Shan') were grown in the greenhouse. These crops were at the mature stage during each experimental period. The leaf area index (about $4.2 \mathrm{~m}^{2} \cdot \mathrm{m}^{-2}$ ) was monitored by a crop canopy analyzer (LAI-2200, LI-COR Inc, USA). The crop temperature was measured by a platinum probe (Pt100, UST Corp, Germany) that was stuck to the lower surface of the leaf.

\section{Microclimate Measurements}

Outside, all climate parameters (wind speed and direction, air temperature and humidity, and solar radiation) were recorded by a meteorological station (WE800, Global Water Instrumentation Inc, USA). This station was located at 2 $\mathrm{m}$ above the ground level and put $30 \mathrm{~m}$ away from the windward direction of the greenhouse. Inside the greenhouse, the air conditions were measured by five air temperature and humidity sensors (PH100TMPA/PH100HUMA, XPH Inc, China) that were imposed in shields to avoid the thermal effect from the solar radiation. They were uniformly placed at $1.5 \mathrm{~m}$ above the ground level along the greenhouse width in the intermediate cross-section of the greenhouse. The net radiation in the greenhouse was monitored by 
A Unit : $m$
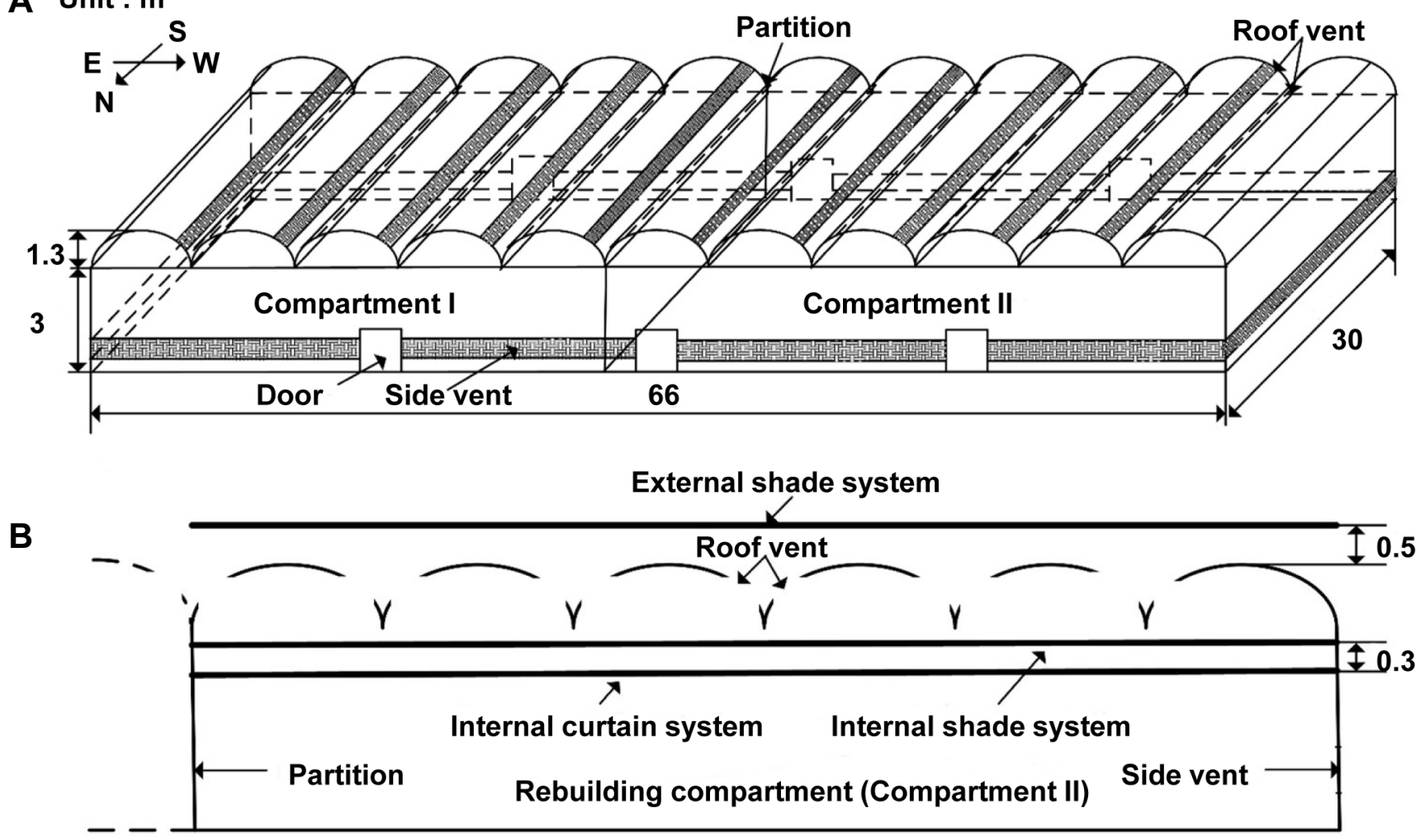

C
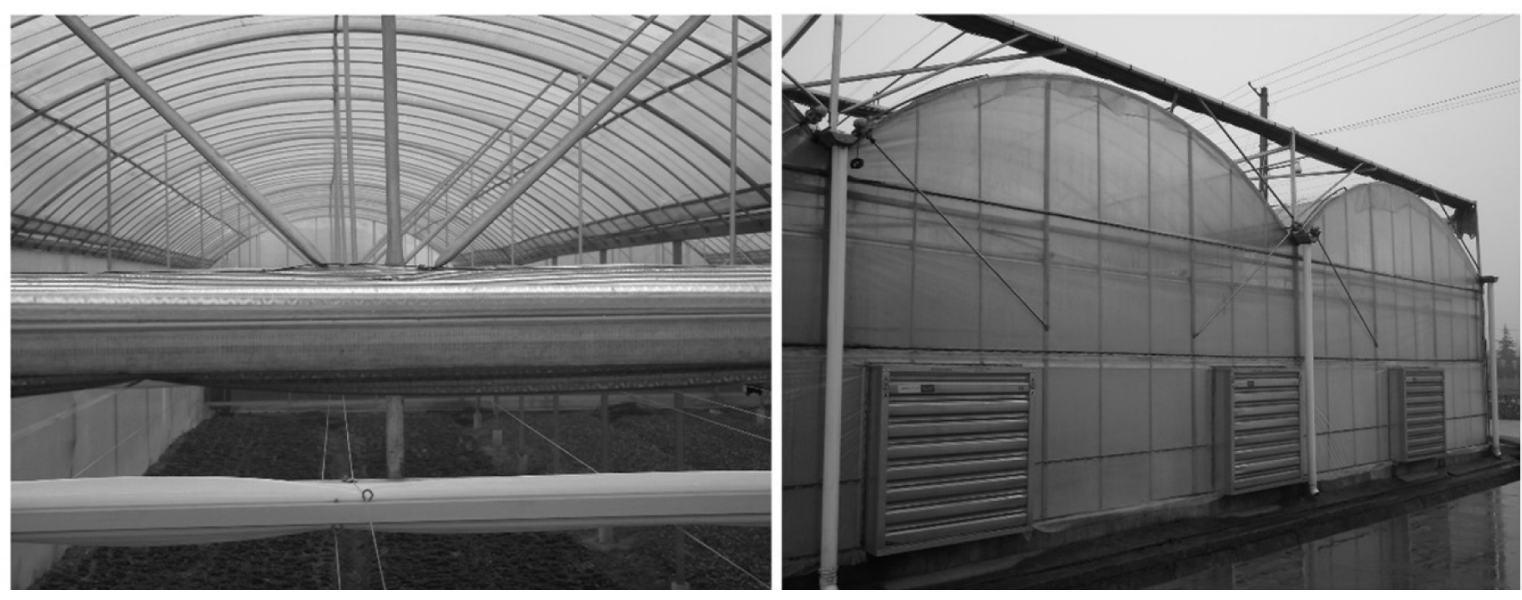

Fig. 1. Sketches of the studied greenhouse. A, geometry of the multi-span plastic greenhouse; B, schematic view of the rebuilding compartment; $\mathrm{C}$, photography of the rebuilding compartment.

a net radiometer (Q-7.1, Campbell Scientific Inc, USA). The temperatures of the ground surfaces were recorded by a hand-held infrared radiation thermometer (CA380, Cason Inc, Hong Kong). The temperatures of plastic covers were measured by Pt100 probes that were fixed on the cover's inner surface.

\section{Statistical Analysis}

Field experiments were performed when outside climate condition was very stable. Most climate parameters were recorded with two data acquisition cards (PCI9112 and PCI9118, ADLINK Technology Inc, Taiwan) at a rate of $10 \mathrm{~Hz}$ and then averaged every $1 \mathrm{~min}$. Statistical analysis 
of the recorded data was performed by the software Matlab (R2007a, Mathwork Inc, USA). These data were used for determining the simulation boundary conditions and validating the simulation model.

\section{Numerical Simulations}

The CFD technique can allow the explicit calculation of the airflow pattern by numerically solving the corresponding transport equations with the finite volume method on a grid. The conservation equations for describing these transport phenomena in the free convection can be written as:

$$
\frac{\partial(u \phi)}{\partial x}+\frac{\partial(v \phi)}{\partial y} \Gamma \nabla^{2} \phi+S_{\phi}
$$

where $\phi$ represents the concentration of the transported quantity in a dimensional form (the momentum, the scalars mass and energy conservation equations), $x$ and $y$ are the Cartesian space coordinates, $\Gamma$ is the diffusion coefficient, $u$ and $v$ are the components of velocity vector, $S_{\phi}$ is the source term, and $\nabla^{2}$ is the Laplace operator.

The airflows inside the natural ventilated greenhouse were highly turbulent (Boulard et al., 2000). The standard $k-\mathcal{E}$ model was thus selected for depicting the turbulent phenomena. The constants of the model were given by Mohammadi and Pironneau (1994). The standard wall function was adopted to account for both the prevailing viscous effect and the strong gradients occurred near the solid wall (Launder and Spalding, 1974). The Boussinesq model was activated to take account of the buoyancy forces. The density was thus treated as the constant value in all equations, except for the buoyancy term in the momentum equation. The species model was activated to calculate the species transport.

The discrete ordinates model (DOM) was employed to account for the influence of solar radiation on greenhouse climate. The gray-band model was activated to simulate the non-gray radiation by dividing radiative spectrum into the solar radiation band [0.4-2.4 $\mu \mathrm{m}]$ and the long wave band [2.4-180 $\mu \mathrm{m}]$. The crop optical parameters were considered to be only valid for the solar radiation band. However, as for other materials, the optical parameters were considered as constants independent of the wavelength band. The radiation calculation was performed once every 10 iterations of the solution process. The beam direction was determined by specifying the vector $(x, y, z)$. The beam width was set to $10^{-6}$. In 2-D CFD calculations, four octants were solved due to symmetry, making a total of $4 N_{\theta} N_{\Phi}$ directions in all. The implementation of radiation model required the optical and thermal properties of materials, as listed in Table 1.

A 2-D CFD model was constructed for the wind almost normal to the greenhouse orientation for all cases. A large computational domain $(264 \mathrm{~m} \times 36 \mathrm{~m})$ composed of a greenhouse and its surroundings was created to describe the atmospheric boundary layer climate and avoid the interference of the domain limit on the inside flow pattern. The pave strategies with $0.1 \mathrm{~m}$ and $0.3 \mathrm{~m}$ triangle grid were adopted to mesh the indoor and outdoor domain, respectively. A $0.05 \mathrm{~m}$ quad grid was adopted to mesh the crop canopy. Meanwhile, a denser grid was taken to mesh the regions close to grounds, roofs, sidewalls, screens and ventilators, where strong gradients may occur. Special attention was paid to mesh the cover and shade materials. The grid dependency was investigated with different grid sizes to ensure that the numerical solution would be independent on the grid resolution. A total number of 543, 700 grids were generated. The choice resulted from a good compromise between a refined grid which required excessive computation time and a coarser one which reduced the accuracy of the numerical calculations. The maximum value

Table 1. Thermal and optical properties of materials involved in the simulation.

\begin{tabular}{lcccccc}
\hline Properties & $\begin{array}{c}\text { Internal } \\
\text { shade screen }\end{array}$ & $\begin{array}{c}\text { External } \\
\text { shade screen }\end{array}$ & $\begin{array}{c}\text { Sidewall/ } \\
\text { partition }\end{array}$ & Roof & Crop & Soil \\
\hline Density $\left(\mathrm{kg} \cdot \mathrm{m}^{-3}\right)$ & 2,750 & 2,750 & 920 & 920 & 1,001 & 2,000 \\
Specific heat $\left.\mathrm{J} \cdot \mathrm{kg}^{-1} \cdot{ }^{\circ} \mathrm{C}^{-1}\right)$ & 900 & 900 & 2,600 & 2,600 & 3,300 & 1,550 \\
Thermal conductivity $\left(\mathrm{W} \cdot \mathrm{m}^{-1} \cdot{ }^{\circ} \mathrm{C}^{-1}\right)$ & 0.90 & 0.90 & 0.33 & 0.33 & 0.4 & 1.58 \\
Absorptivity & 0.45 & 0.35 & 0.92 & 0.06 & 0.95 & 0.9 \\
Scattering coefficient & 0 & 0 & 0 & 0 & 0 & -15 \\
Refractive index & 1.39 & 1.39 & 1.53 & 1.53 & 1.51 & 3 \\
Emissivity & 0.04 & 0.04 & 0.70 & 0.70 & 0.95 & 0.92 \\
\hline
\end{tabular}


of cell skewness is 0.51 .The value of $\mathrm{y}^{+}$criterion is controlled in the validity region (i.e. $20<\mathrm{y}^{+}<200$ ). Hence, the grid quality is proved to be excellent. The detail of grid created in the domain is shown in Fig. 2.

The airflow was considered to be 2-D, incompressible and steady at the domain inlet, where a vertical logarithmic profile of wind velocity (Richards and Hoxey, 1993) was set. The surface roughness length was set to $0.015 \mathrm{~m}$, according to the characteristic of the local terrain. The pressure-outlet type boundary condition was applied to the domain outlet. The no-slipping wall-type boundary condition was set at the upper limit (corresponding to sky) of the domain where the solar and atmospheric radiative fluxes were assumed. The ground was treated as the opaque and diffuse wall. The roof and sidewall were considered as the semi-transparent walls with finite thicknesses. The diffuse fraction of the irradiation was set to $20 \%$ for the roof. The sidewall was treated as the opaque and adiabatic

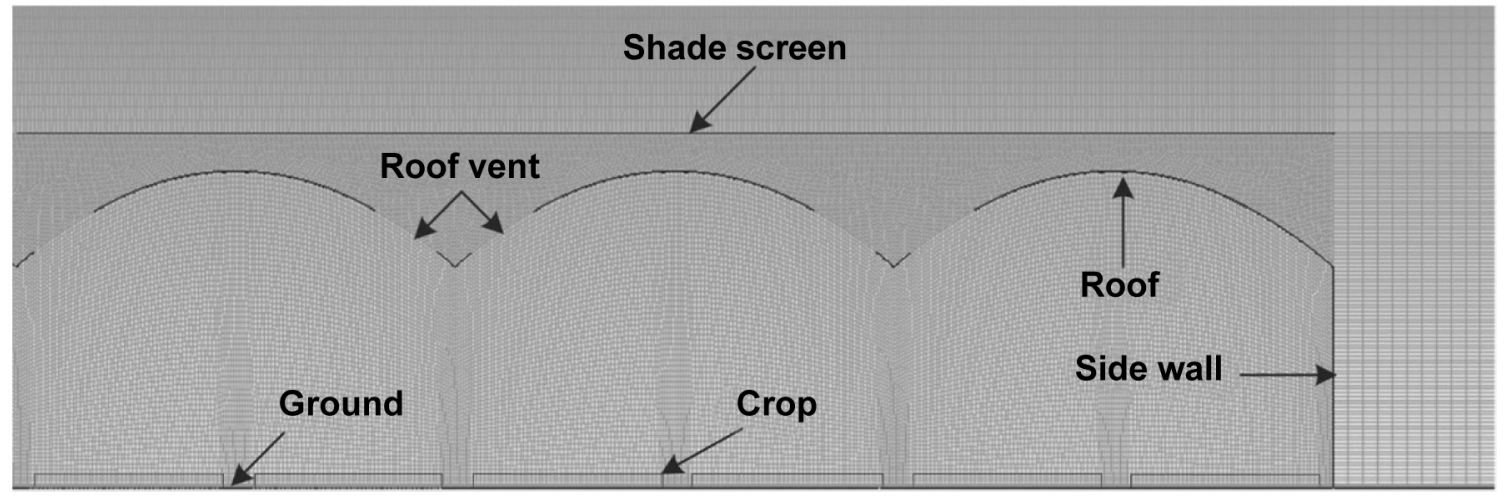

Fig. 2. The grid in the domain.

Table 2. Boundary conditions used in the CFD simulations (Case 1: 15:11-16:30, 6 Aug 2011; Case 2: 12:50-14:00, 15 Aug 2011).

\begin{tabular}{|c|c|c|}
\hline \multirow{2}{*}{ Parameters } & \multicolumn{2}{|c|}{ Values } \\
\hline & Case 1 & Case 2 \\
\hline Air speed $\left(\mathrm{m} \cdot \mathrm{s}^{-1}\right)$ & 1.6 & 1.0 \\
\hline Air temperature $\left({ }^{\circ} \mathrm{C}\right)$ & 28.0 & 31.1 \\
\hline Air relative humidity (\%) & 43 & 50 \\
\hline Air density $\left(\mathrm{kg} \cdot \mathrm{m}^{-3}\right)$ & 1.17 & 1.16 \\
\hline Air specific heat $\left(\mathrm{J} \cdot \mathrm{kg}^{-1} \cdot{ }^{\circ} \mathrm{C}^{-1}\right)$ & $1,006.4$ & $1,006.4$ \\
\hline Air thermal expansion coefficient $\left({ }^{\circ} \mathrm{C}^{-1}\right)$ & 0.00332 & 0.00329 \\
\hline Air thermal conductivity $\left(\mathrm{W} \cdot \mathrm{m}^{-1} \cdot{ }^{\circ} \mathrm{C}^{-1}\right)$ & 0.0262 & 0.0264 \\
\hline Air dynamics viscosity $\left(\mathrm{kg} \cdot \mathrm{m}^{-1} \cdot \mathrm{s}^{-1}\right)$ & $1.86 \times 10^{-5}$ & $1.87 \times 10^{-5}$ \\
\hline Air gravitational acceleration $\left(\mathrm{m} \cdot \mathrm{s}^{-2}\right)$ & & \\
\hline Air absorptivity & & \\
\hline Air scattering coefficient & & \\
\hline Air refractive index & & \\
\hline Air emissivity & & \\
\hline Solar radiation $\left(\mathrm{W} \cdot \mathrm{m}^{-2}\right)$ & 320.0 & 686.0 \\
\hline Net radiation $\left(\mathrm{W} \cdot \mathrm{m}^{-2}\right)$ & 203.0 & 168.0 \\
\hline Leaf surface temperature $\left({ }^{\circ} \mathrm{C}\right)$ & 29.6 & 33.8 \\
\hline Outside ground temperature $\left({ }^{\circ} \mathrm{C}\right)$ & 33.2 & 35.7 \\
\hline Inside ground temperature $\left({ }^{\circ} \mathrm{C}\right)$ & 32.7 & 35.3 \\
\hline
\end{tabular}


material. The input values used for boundary conditions were mainly derived from experimental data, as shown in Table 2. The climate parameters given by Case 2 in Table 2 were used for the case study, since these data can represent more realistic summer climate in eastern China.

Shade screens can introduce a physical resistance, when the airflow moves through them. In order to incorporate this resistance, these screens were modeled by means of the porous medium approach as a source term added to the Navier-Stokes equations. Owing to a lack of wind tunnel facilities, the airflow characteristics of shade screens have to be roughly estimated based on the magnitude orders presented by Miguel et al. (1997), as shown in Table 3. Preliminary simulations confirm that these estimations are reliable, owing to the acceptable discrepancies between experimental results and simulations.

The crop was taken as the porous medium with the drag coefficient of 0.32 to account for its dynamic effect on the airflow. The coupled thermal and vapor transfer between the crop and the ambient air can be customized with user define function (UDF) through the addition of the source term. The details of the implementation are described by Boulard and Wang (2002).

The CFD software package Ansys Fluent 12.0 was used to perform the numerical simulation. The semi-implicit method for the pressured-linked equations (SIMPLE) algorithm was applied to solve the coupled pressure-velocity equations. The body force weighted scheme was adopted for the pressure discretization. The second-order upwind discretization scheme was used to obtain the accuracy of numerical results. The convergence criterion was set to $10^{-6}$ for all variables.

\section{Results}

\section{Validation of the CFD Model}

Fig. 3 compares the experimental and simulated temperatures at a height of $1.5 \mathrm{~m}$ above the ground level inside the greenhouse with roof ventilation. These results are derived with and with no external shade, respectively. For all cases, the differences between the measured and simulated temperature are less than $2^{\circ} \mathrm{C}$. The main reasons for these differences are that: 1) the outdoor wind is assumed to be normal to the greenhouse orientation in the simulation,
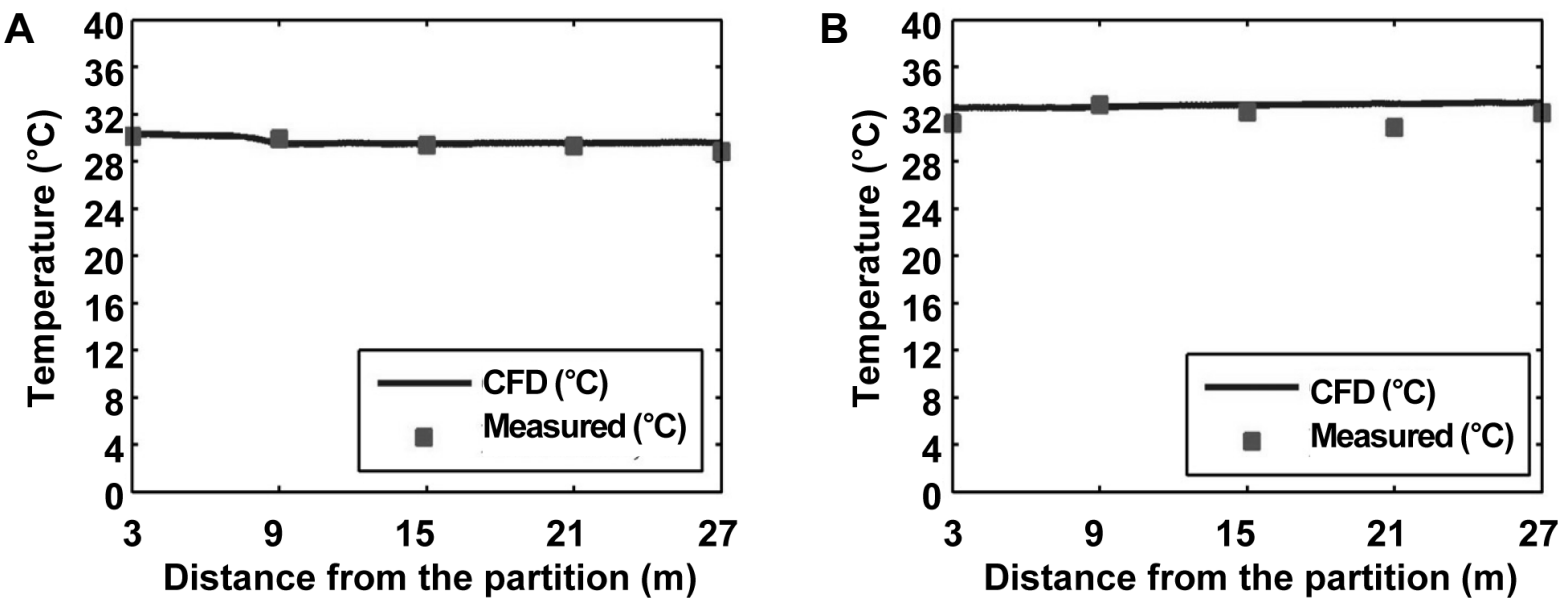

Fig. 3. Comparison of the experimental and CFD simulated temperatures at a height of $1.5 \mathrm{~m}$ above the ground level without shade (A) and with external shade (B).

Table 3. The airflow characteristics of shade materials.

\begin{tabular}{|c|c|c|c|c|c|}
\hline Shade screen & $\begin{array}{c}\text { Screen } \\
\text { porosity }\end{array}$ & $\begin{array}{l}\text { Non-linear momentum } \\
\text { loss coefficient }\end{array}$ & $\begin{array}{l}\text { Permeability } \\
\left(\mathrm{m}^{2}\right)\end{array}$ & $\begin{array}{c}\text { Viscous resistance } \\
\left(\mathrm{m}^{-2}\right)\end{array}$ & $\begin{array}{c}\text { Inertial resistance } \\
\qquad\left(\mathrm{m}^{-1}\right)\end{array}$ \\
\hline External shade screen $^{\mathrm{x}}$ & 0.09 & 7.2 & $7.30 \times 10^{-11}$ & $1.34 \times 10^{10}$ & $1.69 \times 10^{6}$ \\
\hline Internal shade screen ${ }^{\mathrm{y}}$ & 0.05 & 25.4 & $2.85 \times 10^{-11}$ & $3.51 \times 10^{10}$ & $9.52 \times 10^{6}$ \\
\hline
\end{tabular}

${ }^{\mathrm{x}}$ Manufacture data: shade rate of $65 \%$, energy saving rate of $23 \%$ and transmission of $30 \%$.

${ }^{\mathrm{y}}$ Manufacture data: shade rate of $55 \%$, energy saving rate of $65 \%$ and transmission of $45 \%$. 
whereas in reality this wind is not strict to be normal; 2) the leakage of the indoor air to the adjacent compartment or the outdoor environment is not considered in the simulation, whereas in reality this leakage is unavoidable for plastic greenhouses. Nevertheless, the CFD model is reliable, since simulations and experimental data show the similar tendencies and good agreements.

\section{Effect of Shade Combination on the inside Airflow and Temperature Patterns}

Fig. 4 exhibits the airflow and temperature patterns inside the roof ventilated greenhouse with different shade combinations. With no shade (Fig. 4A), most outdoor airflow enters through the second windward roof openings, travels toward the centre and finally escapes through the last roof opening. The temperature pattern shows that the air temperature in the centre, where a strong cross flow passes, is $2-4^{\circ} \mathrm{C}$ lower than the rest of the greenhouse. Meanwhile, the air in the corner is found to be very warm. Especially in the corner of the leeward area, the air temperature reaches up to $36.0^{\circ} \mathrm{C}$.

With external shade (Fig. 4B), the airflow pattern in the greenhouse is similar to that observed with no shade. Greenhouse airflow is properly reduced, but is more uniformly distributed. As the consequences of a better air mixing and a reduced radiative transfer between greenhouse and sky, a more uniform temperature pattern is induced in the greenhouse. It is also noted that, shade screens warm the ambient air. The maximum temperature is as high as $34.8^{\circ} \mathrm{C}$ in the vicinity of shade screens.

With internal shade (Fig. 4C), the exterior airflow penetrates into the greenhouse through the second windward roof opening and then diminishes. Some inlet airflow leaves the greenhouse along the roof surface directly once entering the greenhouse through the roof openings and does not penetrate into the greenhouse interior. Therefore, greenhouse airflow is weaker. High air velocities occur in the vicinity of the lower surface of the internal shade screen. The temperature pattern shows that, as a result of lower air velocities in the first and last span, the air temperature is about $1.5^{\circ} \mathrm{C}$ higher than that obtained with external shade.

With external plus internal shade (Fig. 4D), greenhouse airflow pattern is characterized with similar phenomena to that observed with internal shade, but reduced total airflows through vent openings. The temperature pattern shows that, owe to a strong airflow in the windward area, the air temperature is about $32.5^{\circ} \mathrm{C}$, whereas it increases up to about $34.5^{\circ} \mathrm{C}$ in the leeward area.

\section{Effect of Shade Combination on the inside Climate Distribution}

Fig. 5 shows the horizontal profile of inside air velocity and temperature along the greenhouse width at a height of $1.0 \mathrm{~m}$ above the ground level. For all cases, the air velocity first fluctuates frequently in the first span and then varies at the value around $0.5 \mathrm{~m} \cdot \mathrm{s}^{-1}$ in the other span. The use of shade screens reduces inside temperature

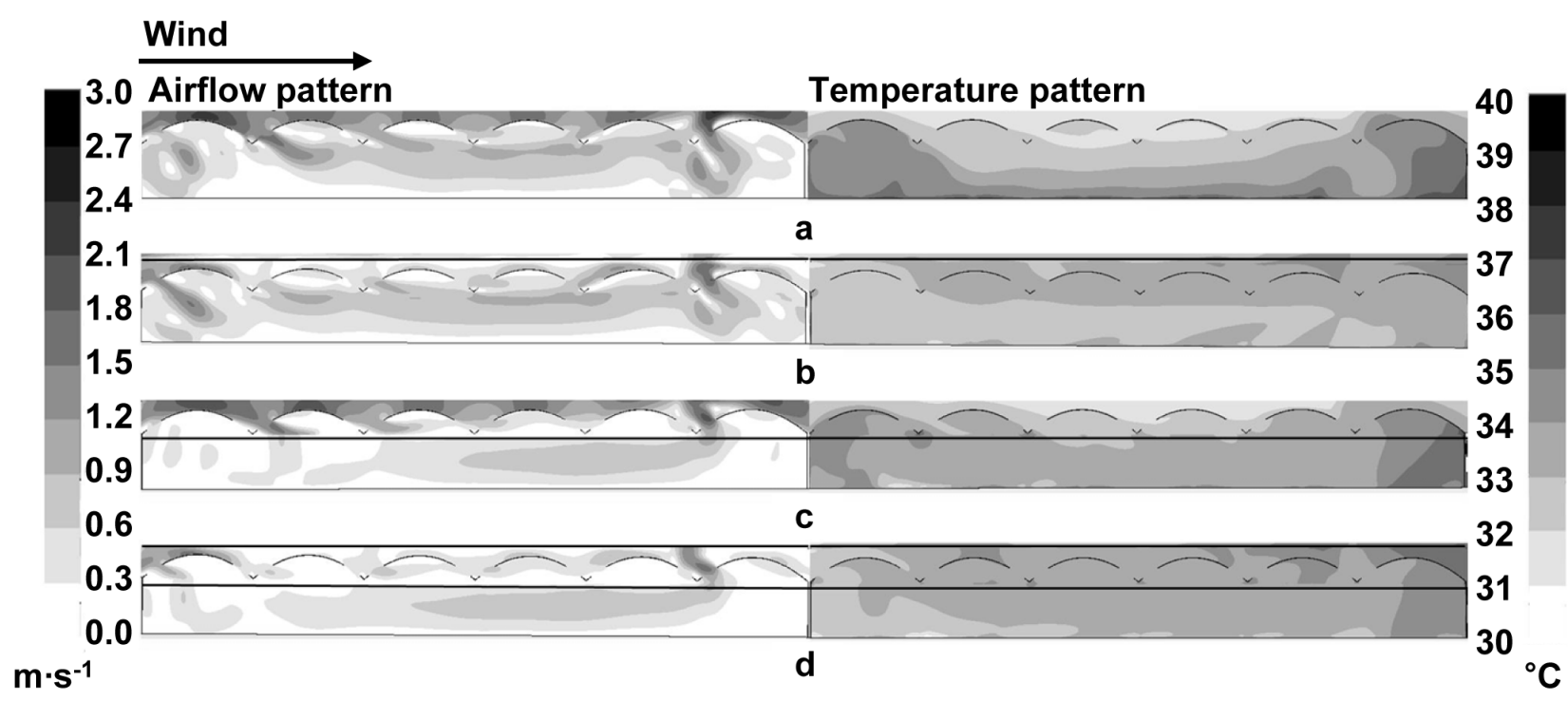

Fig. 4. CFD simulated airflow and temperature patterns inside the greenhouse under different shade combinations. A, no shade;

$\mathrm{B}$, external shade; $\mathrm{C}$, internal shade; $\mathrm{D}$, external plus internal shade. 
and generates a more uniform temperature distribution. The air temperature with the external shade is slightly increased from $32.6^{\circ} \mathrm{C}$ in the windward area to $33.0^{\circ} \mathrm{C}$ in the leeward area. A similar temperature trend can be observed with external plus internal shade, but with higher values. With internal shade, the air temperature profile decreases from $34.0^{\circ} \mathrm{C}$ in the windward area and then in the leeward area tends to coincide with that with external plus internal shade. With no shade, the air temperature is about $0.4-2.0^{\circ} \mathrm{C}$ higher than the other shade combinations. Meanwhile, a larger gradient occurs between the centre and the two sides of the greenhouse.

\section{Effects of Shade Height and Wind Regime on Greenhouse Climate Parameter}

The effect of external shade height on greenhouse climate was investigated with heights of $0.2,0.6,1.0$ and $1.4 \mathrm{~m}$. Fig. 6 compares the mean values of inside air velocity, temperature and relative humidity with these heights. It is clear that, at heights of $0.2,0.6,1.0$ and $1.4 \mathrm{~m}$, the mean values are $0.43,0.44,0.54$ and $0.61 \mathrm{~m} \cdot \mathrm{s}^{-1}$ for air velocity, $33.5,33.2,32.6$ and $32.5^{\circ} \mathrm{C}$ for air temperature, and $44,45,46$ and $47 \%$ for relative humidity, respectively.

The influence of wind regime on shade cooling was explored with wind speeds of $0.5,1.0,1.5$ and $2.0 \mathrm{~m} \cdot \mathrm{s}^{-1}$. Fig. 7 compares the mean values of inside air velocity and temperature with and without external shade under these speeds. For all cases, an increase of outside wind speed results in an increase of inside air velocity. Consequently, greenhouse temperature gradually decreases. It is also observed that, in a wind speed of $0.5-2.0 \mathrm{~m} \cdot \mathrm{s}^{-1}$, the mean

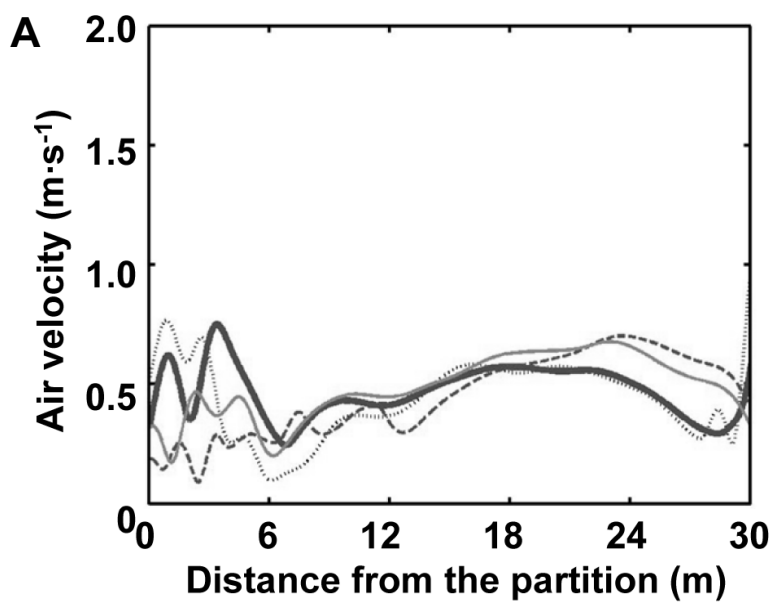

air velocity difference between the shaded and unshaded greenhouse merely varies from 0.01 to $0.04 \mathrm{~m} \cdot \mathrm{s}^{-1}$. The mean air temperature difference between the shaded and unshaded greenhouse reaches up to $1.3^{\circ} \mathrm{C}$ with a wind speed of $0.5 \mathrm{~m} \cdot \mathrm{s}^{-1}$. However, with a wind speed of 2.0 $\mathrm{m} \cdot \mathrm{s}^{-1}$, this temperature difference is reduced to $0.5^{\circ} \mathrm{C}$.

\section{Discussion}

Shade combination results in the similar airflow pattern in the greenhouse. Moreover, it does not have a significant influence on the temperature pattern in the greenhouse. Fig. 4 shows that the use of shade screens reduces $2-4^{\circ} \mathrm{C}$ in the within-crop air temperature that is found to be $1-3^{\circ} \mathrm{C}$ higher than the ambient air temperature in the unshaded greenhouse. The cover temperature falls in the range of $33-39^{\circ} \mathrm{C}\left(2-8^{\circ} \mathrm{C}\right.$ hotter than the outdoor air), owe to heat storage effect. The air temperature varies from 32 to $34^{\circ} \mathrm{C}$ in most regions.

Greenhouse thermal climate is as a result of the joint influences of radiative and convective transfer. The primary mechanism of greenhouse heat transfer is forced convection imposed by the entering air stream. However, solar radiation strongly affects the air temperature in the vicinities of partition, sidewall and roof, where the airflow is weak. Meanwhile, one can also observe that, as the consequences of radiative and convective effect, the temperature profile is not clearly correlated with the air velocity profile in the greenhouse (Fig. 5).

To better control greenhouse shade system, it is necessary to evaluate the influence of shade combination on greenhouse

Fig. 5. Horizontal profiles of inside air velocity (A) and temperature (B) along the greenhouse width at a height of $1.0 \mathrm{~m}$ above the ground level with different shade combinations. …. no shade; — external shade; - - internal shade; - external plus internal shade.

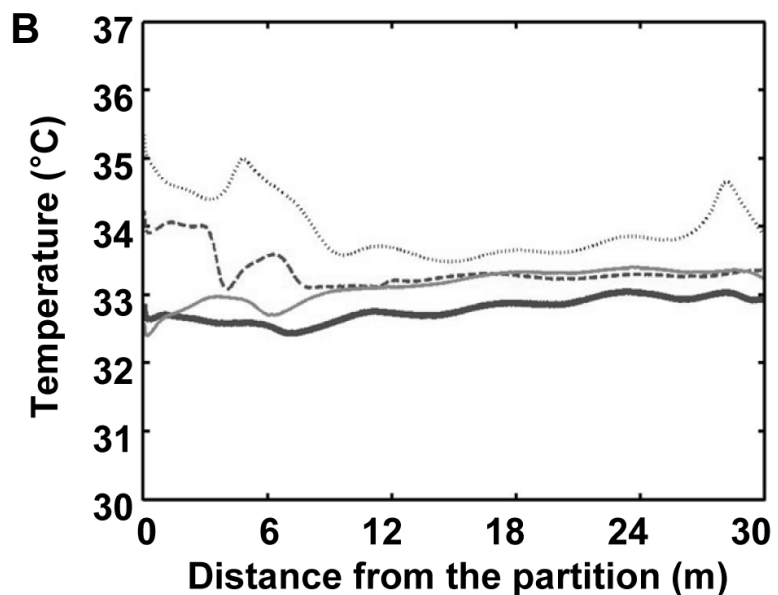



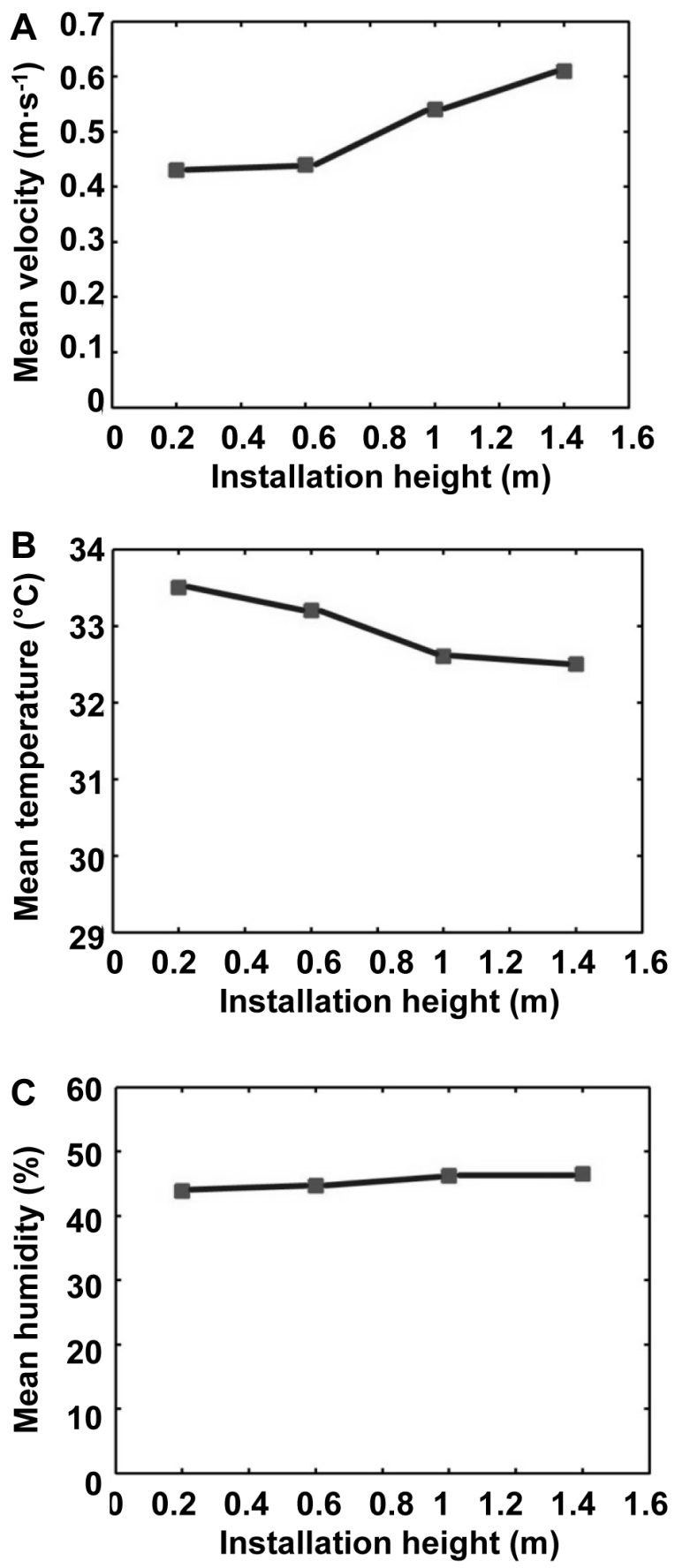

Fig. 6. Histogram of the mean values of the air velocity (A), temperature (B) and relative humidity (C) inside the greenhouse with external shade under installation heights of 0.2 , $0.6,1.0$, and $1.4 \mathrm{~m}$.

climate during the ventilation processes. Table 4 summarizes mean values and standard deviations of inside air velocity, temperature and relative humidity with different shade combinations. It is found that the use of shade screens can reduce air velocity by $0.02-0.20 \mathrm{~m} \cdot \mathrm{s}^{-1}$, lower air temperature by $0.2-0.8^{\circ} \mathrm{C}$ and raise relative humidity level by $0.9-2.0 \%$, according to the arrangement of shade combination. These minor variations reveal that these climate parameters are not influenced significantly by shade screens. This conclusion agrees with the previous results (Lee and Short, 1998). It is also observed that the external shade has a more effective cooling performance than the internal shade. The reason for the explanation is that the majority of the energy absorbed by external shade materials is transferred to the outdoor air. However, the most energy absorbed by internal shade materials still stays in the greenhouse and is used to heat indoor air. Meanwhile, standard deviations of the climate parameters in shaded greenhouses are found to be lower than in unshaded greenhouses, which indicate that the use of shade screens can induce a more homogeneous inside climate. This finding is in consistent with the previous experimental investigation (Kittas et al., 2003).

In the literature, few studies concerned to the information how external shade height influences greenhouse climate parameter. Fig. 6 shows that, in the height of 0-1.0 m, greenhouse temperature and relative humidity are sensitive to the shade height. However, once the height exceeds $1.0 \mathrm{~m}$, these climate parameters are almost independent on the height, which indicates that the external shade has little impact on the exchange between indoor and outdoor air. Owe to the fact that the typhoon often lands in some coastal areas in eastern China, the external shading height should not be too high, otherwise will adversely affect on the structural stability of the shade system. Therefore, from practical engineering views, the external shade tends to be installed within $1 \mathrm{~m}$ above the roof level of the greenhouse.

Shade screens have a strong disturbance to the external factors such as solar radiation and wind regime and consequently generate two contradictory influences on greenhouse climate in a diurnal day. In one hand, they block out the solar radiation entering the greenhouse and reduce the inside temperature. In the other hand, as physical barriers, they impede the exchange between indoor and outdoor air and increase the inside temperature. Fig. 7 exhibits how wind speed affects the cooling capacity of the external shade during the ventilation process. It is clear that, the external shade has a remarkable cooling performance in a less ventilated greenhouse (e.g. $0.5 \mathrm{~m} \cdot \mathrm{s}^{-1}$ ), whereas it has little cooling performance in a more ventilated greenhouse (e.g. $2.0 \mathrm{~m} \cdot \mathrm{s}^{-1}$ ). The main reason is owe to the fact that the decrease of interior air speed, which induces a rise of inside air temperature, has been balanced by 

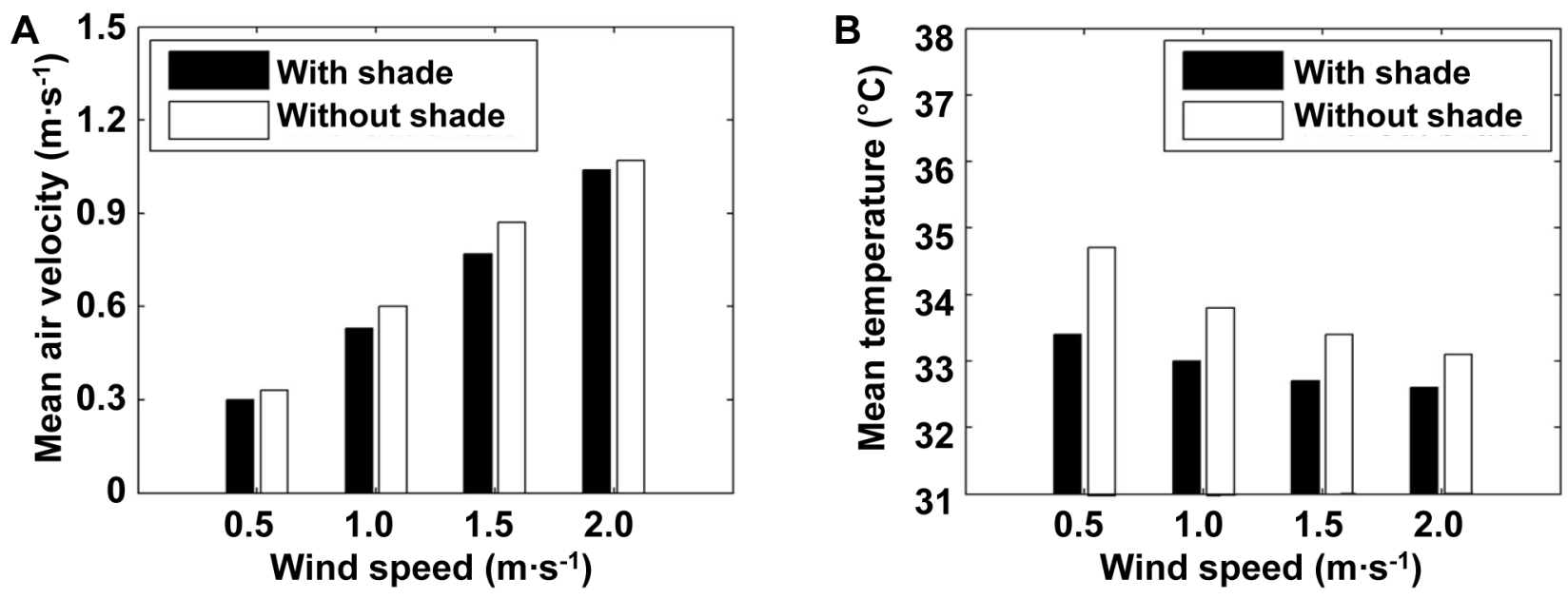

Fig. 7. Histogram of the mean values of the air velocity (A) and temperature (B) in the greenhouse with and without external shade under wind speeds of $0.5,1.0,1.5$ and $2.0 \mathrm{~m} \cdot \mathrm{s}^{-1}$.

Table 4. Mean values and standard deviations of inside air velocity, temperature and relative humidity with different shade combinations.

\begin{tabular}{lcccc}
\hline & \multicolumn{4}{c}{ Shade condition } \\
\cline { 2 - 5 } Parameters & $\begin{array}{c}\text { No } \\
\text { shade }\end{array}$ & $\begin{array}{c}\text { External } \\
\text { shade }\end{array}$ & $\begin{array}{c}\text { Internal } \\
\text { shade }\end{array}$ & $\begin{array}{c}\text { External plus } \\
\text { internal shade }\end{array}$ \\
\hline Mean air velocity $\left(\mathrm{m} \cdot \mathrm{s}^{-1}\right)$ & 0.53 & 0.51 & 0.35 & 0.33 \\
Air velocity standard deviation $\left(\mathrm{m} \cdot \mathrm{s}^{-1}\right)$ & 0.31 & 0.28 & 0.24 & 0.22 \\
Mean temperature $\left({ }^{\circ} \mathrm{C}\right)$ & 33.8 & 33.0 & 33.6 & 33.4 \\
Temperature standard deviation $\left({ }^{\circ} \mathrm{C}\right)$ & 1.20 & 0.36 & 0.72 & 0.49 \\
Mean humidity $(\%)$ & 43.1 & 45.1 & 44.0 & 44.0 \\
Humidity standard deviation $(\%)$ & 2.87 & 0.90 & 1.73 & 1.21 \\
\hline
\end{tabular}

the reduction of incoming solar radiation in the greenhouse, which leads to a decrease of inside air temperature.

In this paper, the effects of shade combination, shade height and wind regime on greenhouse climate were numerically studied. A 2-D CFD model was thus designed based on 11-span plastic greenhouses. The model was first verified with experimental data. Then, it was used to investigate the effects of shade combination, external shade height and wind regime on greenhouse climate. Simulations show that shade combination results in the similar airflow pattern, but slightly alters the temperature pattern inside the greenhouse. The use of shade screens not only slightly affects greenhouse climate parameters, but also reduces the inside climate heterogeneity. The overall assessment of the shade performance shows that the external shade has a good cooling performance and results in a relatively homogeneous inside climate, and can be thus recommended.
In practice, the external shade screen had better be installed within $1 \mathrm{~m}$ above the roof level and is suggested to be actively opened during the period of low wind speed and high-intensity solar radiation in summer. All in all, these greenhouse climate simulations provide a valuable guidance for managing the shade and ventilation system.

\section{Literature Cited}

Al-Arifi, A. 1999. The influence of shading and evapotranspiration on a ventilated greenhouse environment. $\mathrm{PhD}$ Thesis, Ohio State University, Ohio, USA.

Al-helal, I.M. 1998. A computational fluid dynamics study of natural ventilation in arid region greenhouses. $\mathrm{PhD}$ Thesis, Ohio State University, Ohio, USA.

Baxevanou, C.A., D.K. Fidaros, T. Bartzanas, and C. Kittas. 2010. Numerical simulation of solar radiation, air flow and temperature distribution in a natural ventilated tunnel greenhouse. CIGR 


\section{J. 12:48-67.}

Boulard, T. and S. Wang. 2002. Experimental and numerical studies on the heterogeneity of crop transpiration in a plastic tunnel. Comput. Electron. Agric. 34:173-190.

Boulard, T., S. Wang, and R. Haxaire. 2000. Mean and turbulent air flows and microclimatic patterns in an empty greenhouse tunnel. Agr. Forest. Meteorol. 100:169-181.

Cohen, S. and M. Fuchs. 1999. Measuring and predicting radiometric properties of reflective shade nets and thermal screens. J. Agric. Eng. Res. 73:245-255.

Fidaros, D.K., C.A. Baxevanou, T. Bartzanas, and C. Kittas. 2010. Numerical simulation of thermal behavior of a ventilated arc greenhouse during a solar day. Renew. Energ. 35:1380-1386.

Katsoulas, N., A. Baille, and C. Kittas. 2001. Effect of misting on transpiration and conductances of greenhouse rose canopy. Agr. Forest. Meteorol. 106:233-247.

Kichah, A., P.E. Bournet, C. Migeon, and T. Boulard. 2012. Measurement and CFD simulation of microclimate characteristics and transpiration of an impatiens pot plant in a greenhouse. Biosyst. Eng. 112:22-34.

Kitta, E., N. Katsoulas, and D. Savvas. 2012. Shading effects on greenhouse microclimate and crop transpiration in a cucumber crop grown under Mediterranean condition. Appl. Eng. Agric. 28:129-140.

Kittas, C. and A. Baille. 1998. Determination of the spectral properties of several greenhouse cover materials and evaluation of specific parameters related to plant response. J. Agric. Eng. Res. 71:193-202.

Kittas, C., A. Baille, and P. Giaglaras. 1999. Influence of covering material and shading on the spectral distribution of light in greenhouses. J. Agric. Eng. Res. 73:341-351.

Kittas, C., T. Bartzanas, and A. Jaffrin. 2003. Temperature gradients in a partially shaded large greenhouse equipped with evaporative cooling pads. Biosyst. Eng. 85:87-94.

Launder, B.E. and D.B. Spalding. 1974. The numerical computation of turbulent flows. Comput. Method. Appl. M. 3:269-289.

Lee, I.B. and T.H. Short. 1998. Predicted effects of internal horizontal screens on natural ventilation of a multi-span greenhouse. In: 91st Annual International Meeting of ASAE, Paper No. 987014, Orlando, FL, USA, July 12-16.

Miguel, A.F., N.J. van de Braak, and G.P.A. Bot. 1997. Analysis of the airflow characteristics of greenhouse screening materials. J. Agric. Eng. Res. 67:105-112.
Mohammadi, B. and O. Pironneau. 1994. Analysis of the k-epsilon turbulence model. Wiley, New York, Masson, Paris.

Montero, J.I., P. Muñoz, M.C.Sánchez-Guerrero, E. Medrano, D. Piscia, and P. Lorenzo. 2013. Shading screens for the improvement of the night-time climate of unheated greenhouses. Spain. J. Agr. Res. 11:32-46.

Muñoz, P., J.I. Montero, A. Anton, and N. Iglesias. 2004. Computational fluid dynamic modelling of night-time energy fluxes in unheated greenhouse. Acta Hort. 691:403-410.

Nebbali, R., J.C. Roy, and T. Boulard. 2012. Dynamic simulation of the distributed radiative and convective climate within a cropped greenhouse. Renew. Energ 43:111-129.

Piscia, D., J.I. Montero, E.J. Baeza, and B.J. Bailey. 2012a. A CFD greenhouse night-time condensation model. Biosyst. Eng. 111:141-154.

Piscia, D., J.I. Montero, M. Melé, J. Flores, J. Perez-Parra, and E.J. Baeza. 2012b. A CFD model to study above roof shade and on roof shade of greenhouses. Acta Hort. 952:133-139.

Richards, P.J. and R.P. Hoxey. 1993. Appropriate boundary conditions for computational wind engineering models using the $\mathrm{k}-\varepsilon$ turbulence model. J. Wind. Eng. Ind. Aerod. 46-47:145-153.

Sapounas, A.A., S. Hemming, H.F. De Zwart, and J.B. Campen. 2010. Influence of insect nets and thermal screens on climate conditions of commercial scale greenhouses: A CFD approach, p. 1-11. In: XVII ${ }^{\text {th }}$ World Congr. Intl. Commission Agricultural Biosystems Eng. (CIGR). Québec, Canada, 13-17 June, 2010.

Tong, G., D.M. Christopher, and B. Li. 2009. Numerical modelling of temperature variations in a Chinese solar greenhouse. Comput. Electron. Agric. 68:129-139.

Vlamdimirova, S.V., R.A. Bucklin, and D.B. McConnel. 1996. Influence of shade level, wind velocity, and wind direction on interior air temperatures of model shade structure. Trans. ASAE 39:1825-1830.

Willits, D.H. 2000. Intermittent application of water to an externally mounted, greenhouse shade cloth to modify cooling performance. Trans. ASAE 43:1247-1252.

Willits, D.H. 2001. The effect of cloth characteristics on the cooling performance of external shade cloths for greenhouses. J. Agric. Eng. Res. 79:331-340.

Willits, D.H. 2003. The effect of cloth temperature on the cooling efficiency of shade clothes in greenhouses. Trans. ASABE 46:1215-1221. 